\title{
Nitrite Concentrations in Commercial Dog Foods
}

\author{
Jun Kobayashi' ${ }^{*}$, Yukiko Fujikake ${ }^{1}$, Miho Ishida ${ }^{1}$, Keiichi Ikeda ${ }^{2}$ and Hideo Sugiyama ${ }^{3}$ \\ ${ }^{1}$ Faculty of Veterinary Medicine, Nippon Veterinary and Life Science University, Tokyo, Japan \\ ${ }^{2}$ Faculty of Pharmaceutical Sciences, Hokuriku University, Ishikawa, Japan \\ ${ }^{3}$ Graduate School of Health Sciences, Matsumoto University, Nagano, Japan
}

\begin{abstract}
The nitrite concentrations in different commercial dog foods were measured. Differences in the nitrite concentrations were observed, and were mainly attributed by the type of meat used as the main ingredient and its proportion in the final product. Standard doses for nitrite of 2.5 and $4.6 \mathrm{mg} / \mathrm{kg}$ were calculated using different methods, and these values are both much lower than the standard dose for human food. The nitrite concentrations in some of the samples in this study exceeded the $2.5 \mathrm{mg} / \mathrm{kg}$ value.
\end{abstract}

Keywords: Nitrite; Food additive; Dog food; Total nutrition

\section{Introduction}

In recent years, it has become common for dogs and cats in Japan to be considered more as companion animals than pets, and these animals are often treated as family members. There are many dedicated products that owners can choose to purchase for their pets, including foods, medications, toys, clothing, and cleaning products [1]. Because many of these products are similar to those used by humans, they are often erroneously assumed to meet similar quality and safety standards. Unfortunately, these products are not always safe [2-4]. There are few legal regulations for food produced for animals, and inexpensive raw materials are often used and the protocols for preservation are not stringent $[5,6]$.

Foods prepared for humans are not necessarily nutritious for other animals. Ingredients that may be harmless to humans can be toxic to animals, and ingredients that are not required for humans may be an indispensable for animals. Therefore, human food cannot be used for animals. Pet owners can obtain information from veterinarians and veterinary technicians on how to prepare fresh food for their pets. However, pet food preparation is time consuming, and many pet owners choose to simply purchase over-the-counter pet food. With over-the-counter pet food, consumers do not usually have information on the manufacturing process, exact contents, transportation method, and storage $[3,5,7]$. For human food, Japanese law requires that food packaging identifies the main ingredient and food additives used in the product. The additives used in human food products have been investigated in toxicity studies, and the amounts added to food are regulated so that they are not harmful even with regular consumption over a lifetime. By contrast, manufacturers of pet food are not required to identify food additives or the main ingredients on products sold in Japan [7]. Moreover, on small packages of pet food, the contents are often written in an abbreviated form, which means they are not readily identifiable by the purchaser [7].

Sodium nitrite is often included in meat products for human consumption to produce a red color, and is typically used at a dose of less than $70 \mathrm{mg}$ of nitrite (from nitrous acid) per kilogram of meat [8]. This compound combines with hemoglobin and myoglobin in the meat to produce a color similar to fresh blood, which gives the product an appearance of freshness. Sodium nitrite also acts as a preservative [2], and suppresses propagation of pathogenic Escherichia coli $\mathrm{O} 157$ and Clostridium botulinum $[9,10]$. However, nitrite can combine with amines in food and form carcinogenic nitrosamines and cause methemoglobinemia [11-13]. Whereas humans may select food based on its color, this is likely not important for dogs because they have limited color perception [14]. The European Union has set a maximum level for nitrite in pet food of $100 \mathrm{mg} / \mathrm{kg}$ for food with a water content of $>20 \%$ [15], but there are no similar standards in the United States or Japan [15-17].

The aim of the present study was to measure the nitrite concentrations in several different dog foods to correlate changes in the concentrations with differences in the products (e.g., type of meat, packaging, manufacturer) [18], and to establish a standard dose for future safe use of additives in dog food.

\section{Materials and Methods}

\section{Dog food samples}

Seventeen commercially available dog foods from different manufacturers were purchased from local stores between December 2013 and December 2014 (Table 1). The products were classified based on their water content as semi-dry (10-30\% water), semi-moist (25-35\% water), or wet (about $75 \%$ water) [19]. The products were packaged in bags, pouches, and cans [2].

\section{Reagents}

The nitrite concentration was measured using an established method [19]. First the product was pretreated using zinc hydroxide under alkaline conditions in an $80^{\circ} \mathrm{C}$ water bath to remove fat and protein and extract the nitrite ion. Then, the nitrite was calorimetrically quantified using a diazo-coupling reaction $[20,21]$. For these reactions, the following solutions were prepared: ammonium acetate (10\%) in water, sulfanilamide $(0.5 \%)$ in $6 \mathrm{~mol} / \mathrm{L}$ hydrochloric acid, and a naphthylethylenediamine solution of $N$-(1-naphtyl) ethylenediamine

*Corresponding author: Jun Kobayashi, School of Veterinary Nursing and Technology, Faculty of Veterinary Medicine, Nippon Veterinary and Life Science University, 1-7-1 Kyonan-cho, Musashino, Tokyo 180-8602, Japan, Tel: +81422314151; Fax: +81422332094; E-mail: junkoba@nvlu.ac.jp

Received July 11, 2016; Accepted August 01, 2016; Published August 05, 2016

Citation: Kobayashi J, Fujikake Y, Ishida M, Ikeda K, Sugiyama H (2016) Nitrite Concentrations in Commercial Dog Foods. J Vet Sci Technol 7: 369. doi: 10.4172/2157-7579.1000369

Copyright: @ 2016 Kobayashi J, et al. This is an open-access article distributed under the terms of the Creative Commons Attribution License, which permits unrestricted use, distribution, and reproduction in any medium, provided the original author and source are credited. 


\begin{tabular}{ccccc}
\hline $\begin{array}{c}\text { Sample } \\
\text { No. }\end{array}$ & Manufacturer & Included meat and its product & Water & Package \\
\hline 1 & Y & chicken & semi-dry & bag \\
2 & chicken & semi-dry & bag \\
3 & I & chicken & wet & pauch \\
4 & I & chicken & wet & pauch \\
5 & D & chicken & wet & can \\
6 & $\mathrm{D}$ & beef, chicken & wet & can \\
7 & $\mathrm{M}$ & beef & wet & can \\
8 & $\mathrm{M}$ & beef, chicken & wet & can \\
9 & $\mathrm{M}$ & beef, chicken & wet & pauch \\
10 & $\mathrm{M}$ & beef, chicken & wet & pauch \\
11 & $\mathrm{M}$ & beef, chicken & wet & pauch \\
12 & $\mathrm{M}$ & beef & wet & can \\
13 & $\mathrm{H}$ & chicken, pork, chicken extract & wet & can \\
14 & $\mathrm{H}$ & beef, pork, chicken extract & wet & can \\
15 & $\mathrm{H}$ & turkey, pork, chicken extract & wet & can \\
16 & $\mathrm{~N}$ & chicken, beef, fish extract & semi-moist & bag \\
17 & $\mathrm{~K}$ & chicken, fish & semi-moist & bag \\
\hline
\end{tabular}

Table 1: Dog food samples used in this study.

hydrochloride $(0.12 \%)$ in water. A nitrite stock solution was prepared by dissolving sodium nitrite $(30 \mu \mathrm{g} / \mathrm{mL}$ for nitrite) in water. After dividing into $1 \mathrm{~mL}$ aliquots, this solution was frozen at $-20^{\circ} \mathrm{C}$ until required for use. This solution was used to prepare the calibration curve and controls $(0.6 \mu \mathrm{g} / \mathrm{mL})$ and was diluted with water (dilution faction $=1 / 500$ ) just before use. All reagents used were special grade and purchased from Wako Pure Chemical Industries (Osaka, Japan). Ultrapure water (18 M $\Omega \cdot \mathrm{cm}$, Merck Millipore, Billerica, MA) was used in all experiments.

\section{Pretreatment of dog food samples}

An established method was used to extract nitrite ion from the dog food samples using a quarter of the sample mass and reagent volumes compared with the original method [22]. A $2.5 \mathrm{~g}$ sample of each dog food was added to a small volume of hot water in a mortar and pestle and crushed to a smooth paste. The sample was then transferred to a $50 \mathrm{~mL}$ centrifuge tube and $2.5 \mathrm{~mL}$ of $0.5 \mathrm{~mol} / \mathrm{L}$ sodium hydroxide, 2.5 $\mathrm{mL}$ of $12 \%$ zinc sulfate, and hot water $\left(80^{\circ} \mathrm{C}\right)$ were added to reach a total volume of approximately $40 \mathrm{~mL}$. Then, the mixture was heated in an $80^{\circ} \mathrm{C}$ water bath for $20 \mathrm{~min}[2,18]$. After heating, the tube was cooled to room temperature, and $5 \mathrm{~mL}$ of ammonium acetate solution was added. Then water was added to make up the volume to $50 \mathrm{~mL}$. After centrifugation at $3000 \mathrm{rpm}$ for $5 \mathrm{~min}$ at $4^{\circ} \mathrm{C}$, the supernatant was filtered through filter paper (Advantec Toyo; Tokyo, Japan) to obtain a transparent test solution.

\section{Measurement of nitrite concentration}

Measurements were conducted with samples $1 / 10^{\text {th }}$ of the volume compared with the original method [19]. To a $2 \mathrm{~mL}$ aliquot of each test solution, $0.1 \mathrm{~mL}$ of sulfanilamide solution and $0.1 \mathrm{~mL}$ of naphthylethylenediamine solution were added. After standing at room temperature for $20 \mathrm{~min}$, the absorbance at $540 \mathrm{~nm}$ was measured against water as the reference [21]. A calibration curve prepared from standard solutions of nitrite $(0-0.6 \mu \mathrm{g} / \mathrm{mL})$ was used to estimate the nitrite concentration in the test solution. If the test solution was colored or turbid, $0.2 \mathrm{~mL}$ of water was added instead of the sulfanilamide and naphthylethylenediamine solutions. The solution was used for a blank. The nitrite concentrations in the samples were estimated from the calibration curve using their absorbance values.

\section{Statistical analysis}

Results are presented as mean \pm standard deviation. Data were statistically analyzed using Student's $t$-test. A $p$ value less than 0.05 was considered to represent a statistically significant difference.

\section{Results and Discussion}

\section{Calibration curve}

The calibration curve is shown in Figure 1. Among the reagents used, the naphthylethylenediamine solution was susceptible to oxidation in air, and this solution gradually became brown with long-term storage. As this reagent deteriorated, the background signal increased. In addition, nitrite is very unstable. Both reduction to ammonium ions by coexisting substances such as proteins, and oxidation to nitrate ions by metal or air can occur. Therefore, to obtain accurate data, samples should be analyzed as soon as possible after extraction of nitrite. In this study, samples were analyzed on the day of extraction and were compared with a freshly prepared calibration curve. If it was not possible to analyze the sample on the day of extraction, a nitrite standard solution $(0.6 \mu \mathrm{g} / \mathrm{mL})$ was prepared and stored at the same time as the filtrate from the dog food sample. The results from the stored standard solution were used for correction of the results from the dog food sample after analysis. Each sample was analyzed in triplicate or quadruplicate $[23,24]$.

\section{Methods}

The samples used in this study had different water contents, hardness, and diversity. The semi-dry food had to be ground before analysis, whereas the wet food did not. Therefore, the pretreatment was very different among the samples.

When heated for extraction, some extracts were white and turbid. This probably arose from fats and proteins in the dog food samples. Any white precipitates were removed by filtration to obtain a clear and colorless filtrate. The absorbance of the blank, which did not produce a color, was almost zero.

Crystals of sodium nitrite are affected by water and oxidation in air $[13,25]$. However, one study found that solutions of nitrite were stable and concentration changes did not occur with exposure to light or heating $\left(60^{\circ} \mathrm{C}\right)$ for 60 days [26]. Nitrite is also reportedly stable in alkaline solutions [24]. In this study, to ensure that the reagents were at the required concentrations they were freshly prepared every other month. Before use, the nitrite stock solution was frozen at $-20^{\circ} \mathrm{C}$, and all other reagents were refrigerated. This meant that degradation of the reagents should not affect the results.

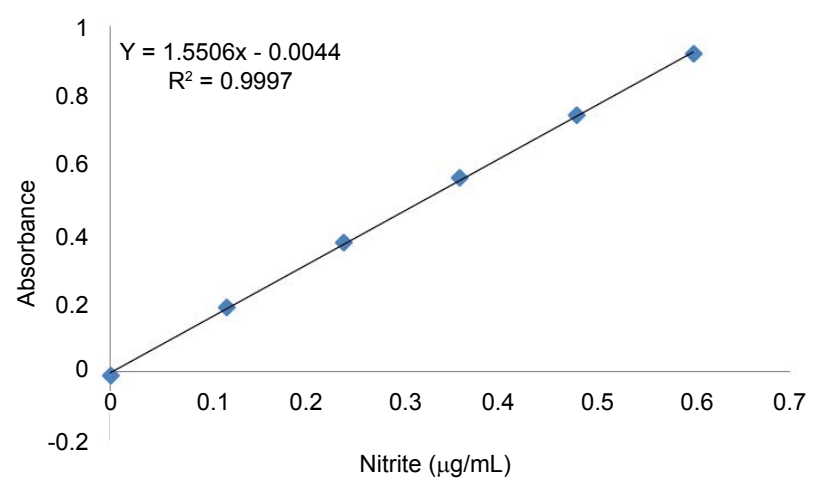

Figure 1: Calibration curve for nitrite. 


\section{Nitrite concentrations}

The nitrite concentrations (Table 2) for the samples showed that imported dog food and wet dog food had higher nitrite concentrations than the other dog food samples. Sample 7 showed a particularly high nitrite concentration $(4.4 \mathrm{mg} / \mathrm{kg})$. This sample was reddish in appearance, and had a color similar to fresh meat [10]. Dog food products made from different meats and with different packaging, water contents, and manufacturers could have different nitrite concentrations. Nitrite has been detected at low concentrations even in vegetable products that do not identify it on the product label, but it is not known whether this arises from nitrite already present in the vegetables or that has been added $[10,13]$. When sodium nitrite is added during food production, only $1 / 6^{\text {th }}$ to $1 / 8^{\text {th }}$ of the original concentration remains in the food product after processing [10]. The concentration remaining in the food product appears to vary depending on the storage period and temperature. Bacteria in the mouth and intestines can also form nitrite [27]. One study found that nitrite, nitrothiol, and nitrosomyoglobin formed in salted processed meat on storage for 7 days [28].

\section{Causes of changes in the nitrite concentrations}

The results were classified according to the type of meat, packaging, and water content, and plotted (Figures 2-4). Most of the dog food samples contained either chicken, beef, or chicken and beef. This result is consistent with the sample 7 is high. The nitrite concentration in the beef group was significantly higher $(\mathrm{P}<0.05)$ than the concentrations in the other two groups. There was no significant difference between the other two groups. The high concentration in the beef products could be attributed to the higher levels of myoglobin in the beef compared with chicken and pork [29]. Meats with higher levels of myoglobin require more sodium nitrite for sufficient color development. When beef is mixed with other meats such as chicken, the level of myoglobin is lower and less nitrite needs to be added.

We also compared the nitrite concentrations for products packaged in plastic bags, pouches, and cans (Figure 3). The products in cans had the highest nitrite concentrations among these three types of packaging. There was not a significant difference between the nitrite concentrations for the products packaged in plastic bags and pouches. The significant difference between pouches and cans cannot be caused

\begin{tabular}{ccc}
\hline Sample No. & Nitrite $(\mathrm{mg} / \mathrm{kg})$ & Display of nitrite addition \\
\hline 1 & $0.452 \pm 0.130$ & \\
2 & $0.459 \pm 0.080$ & \\
3 & $0.579 \pm 0.106$ & \\
4 & $0.651 \pm 0.295$ & \\
5 & $0.431 \pm 0.156$ & \\
6 & $3.992 \pm 0.510$ & \\
7 & $4.397 \pm 1.273$ & \\
8 & $0.213 \pm 0.049$ & \\
9 & $0.520 \pm 0.111$ & \\
10 & $0.320 \pm 0.131$ & \\
11 & $0.371 \pm 0.091$ & \\
12 & $3.824 \pm 1.142$ & \\
13 & $0.138 \pm 0.168$ & \\
14 & $0.160 \pm 0.110$ & \\
15 & $0.394 \pm 0.097$ & \\
16 & $0.235 \pm 0.078$ & \\
17 & $1.018 \pm 0.703$ & \\
\hline
\end{tabular}

Nitrite concentrations are the average \pm standard deviation $(n=4)$

Table 2: Nitrite concentrations in the pet food samples.

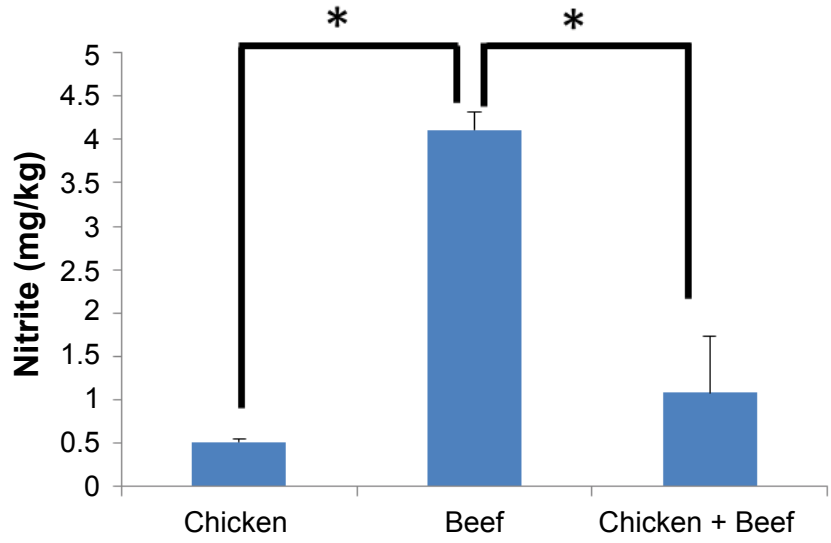

Figure 2: The nitrite concentrations for dog foods prepared from chicken $(n=5)$, beef $(n=2)$, and a mix of chicken and beef $(n=5)$. Results are the average \pm standard error, and ${ }^{*}$ indicates a significant different $(\mathrm{P}<0.05)$

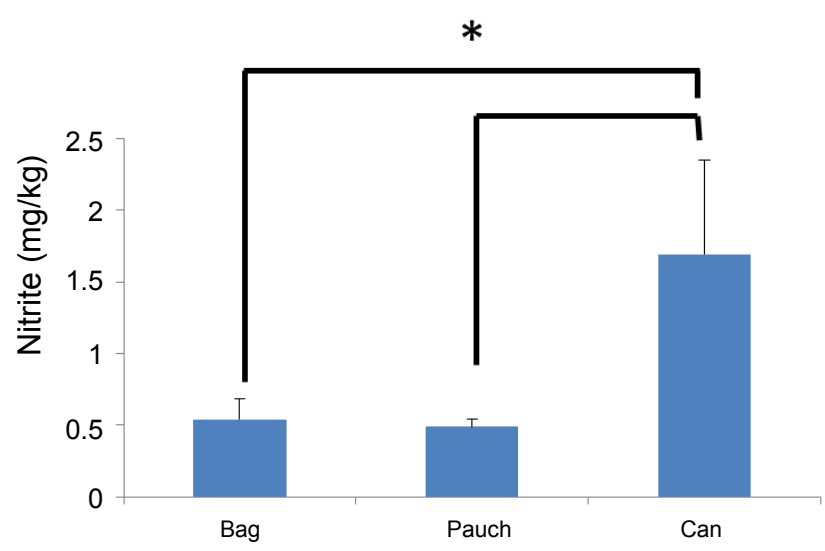

Figure 3: The nitrite concentrations for dog foods packaged in plastic bags $(n=4)$, pouches $(n=5)$, and cans $(n=8)$. Results are the average \pm standard error, and ${ }^{*}$ indicates a significant different $(P<0.05)$.

by differences in the product storage life because pouches and cans can usually be stored for a similar period. These results suggest that changes in the nitrite concentration are not related to the type of packaging.

Finally, the nitrite concentrations were compared based on the water content of each dog food (Figure 4). Among the groups (semimoist, semi-dry, and wet), the wet food had the highest concentration of nitrite. This suggests that bacterial propagation occurred, and the nitrite concentration decreased. When sodium nitrite is used as an additive, it affects the exterior color of the food. It has been reported that a sodium nitrite concentration higher than any detected in this study is required to suppress growth of Clostridium botulinum. Therefore, at the concentrations detected in this study, it is unlikely that sodium nitrite has been added for bacterial growth suppression. The nitrite concentration in the products is probably not related to the water content.

Among the wet foods that we tested (Table 1), we compared the nitrite concentrations for products from different manufacturers (data not shown). The packaging of some of these products claimed that they were preservative- and additive-free, and our results did show some differences between products from these manufacturers and other manufacturers. Dog foods made by companies D and M contained 


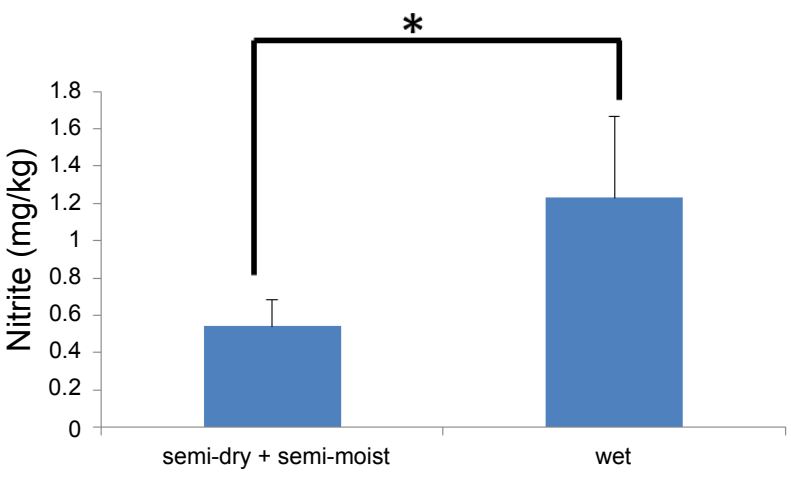

Figure 4: The nitrite concentrations for semi-dry $(n=4)$, semi-moist $(n=4)$, and wet $(n=13)$ dog foods. Results are the average \pm standard error, and ${ }^{*}$ indicates a significant different $(\mathrm{P}<0.05)$.

higher concentrations of nitrite than the average, which was consistent with these products containing a high proportion of beef. Overall, these results show that the type of meat is important in determining the concentration of sodium nitrite added to a product and the residual concentration remaining after processing.

\section{Standard dose}

Research conducted on salted sausages for human consumption has shown that the redness increases as the amount of nitrite added to the product increases, and that nitrite also improves the taste and smell [30]. If only the color is affected by the addition of sodium nitrite to dog food products, then its main function is to appeal to owners when making purchasing decisions, and it is not needed to maintain the quality of the food. However, if nitrite also affects the taste and smell of the product for dogs, then it is also associated with palatability and could ensure continuous consumption of a particular product. In the present study, a standard dose of nitrite in dog food was estimated from that specified for human food.

First, a standard dose was calculated from the daily intake. Among the meat products available for human consumption, processed meats are the most similar to dog food. Therefore, the standard dose for nitrite $(\leq 70 \mathrm{mg} / \mathrm{kg})$ in processed meats was used in this study. The average intake of ham and sausages in Japan is $13.25 \mathrm{~g} /$ day [31]. Assuming a daily intake of wet dog food of $200 \mathrm{~g}$ per kilogram of body weight, a standard dose for nitrite in dog food was calculated at $4.6 \mathrm{mg} / \mathrm{kg}$. Pet Food Safety laws are based on a water content of $10 \%$, and this was used to adjust the nitrite content to $27.6 \mathrm{mg} / \mathrm{kg}$.

Next, a standard dose was calculated from the acceptable daily intake of nitrite for humans $(0.07 \mathrm{mg}$ per kilogram of body weight per day) [32]. Using the same daily intake of wet dog food (200 g per kilogram of body weight) as in the first calculation. A value of $0.4 \mathrm{mg} /$ $\mathrm{kg}$ was calculated, and then adjusted to $2.5 \mathrm{mg} / \mathrm{kg}$ for the water content.

In this study, none of the dog food samples exceeded the standard dose determined from the daily intake. However, some samples did exceed the standard dose obtained from the acceptable daily intake. These calculations included many assumptions, and the results are only approximate. Future calculations should take into account metabolic differences between dogs and humans, dog breeds, and dogs of different ages. Because dogs often eat the same diet over their lifetime, and have less variety in their diets than humans, it is more important to set strict standard doses than it is for foods for human consumption.
The Ministry of Agriculture, Forestry and Fisheries and Ministry of the Environment in Japan have suggested a nitrite standard dose for pet food of $\leq 100 \mathrm{ppm}$ [33]. However, this value was derived from that for human food products, and our results suggest that it is too high.

\section{Conclusions}

Currently, the use of sodium nitrite in dog food is not regulated in Japan. However, many voluntary regulation steps have been taken $[15,34]$, and in future it is expected that its use will be restricted by law in Japan $[17,33]$. In future research we will analyze more dog food samples and other types of pet food for nitrite. We have previously analyzed pet food for heavy metals $[1,4,17,35]$, and we believe that want to do the verification of the hazard.

\section{References}

1. Spex CertiPrep Co. Investigation of hazardous heavy metals (minerals) contained in the pet food - Pet food case files.

2. Fujii T (2010) For commercial pet food. J Pet Anim Nutr 13: S4-S7.

3. Kusaba H (2011) Small Animal Practice and Pet Food. J Pet Anim Nutr 14 42-44.

4. Terachi T, Funaba M, Matsui T (2011) Heavy metal concentration in canned cat foods. J Pet Anim Nutr 14: 18-22.

5. How to choose a dog food.

6. Component of dog food - Additive list and details of the components of the food

7. Crying for the dog food in a mutter.

8. Sato K (2010) Trend in food additives administration of Japan. Shokuhin Eiseigaku Zasshi (J Food Hyg Soc Japan) 51: 331-335.

9. Darmadji P, Izumimoto M (1994) Effects of chitosan and nitrite on the properties of fermented meat. Anim Sci Technol 65: 639-646.

10. Hioki S, Katou H, Itaya H, Shimada K, Tatsumi R, et al. (1997) Effects of sodium nitrite and common salt on quality of sausage. Res Bull Univ Farm Hokkaido Univ 30: 55-60.

11. Yasuhiro G (2000) Spectrophotometric determination of nittrate and nitrite in natural water samples based on an oxime formation reaction of phenol Bunseki Kagaku 49: 261-264.

12. Nakashima $Y$, Suzuki S, Yamazaki M, Inoue $Y$, Fukatsu $Y$, et al. (2010) Determination of nitrite and nitrate in meat products by inline dialysis ion chromatography. Bunseki Kagaku 59: 679-683.

13. Terajima K, Watanabe T, Hioki A, Kubota M (1990) Preparation of nitrate and nitrite ion standard solutions. Report of Chem Eng Lab 85: 55-59.

14. It looks OK in the sodium nitrite? - Chase additives of pet food!

15. Food Inspection Center, Visionbio Co.: Pet food safety inspection.

16. Oshima S (2010) Pet food safety law-One Year after Enforcement and beyond. J Pet Anim Nutr 13: 74-80.

17. Asami $Y(2010)$ The standards and specifications for undesirable substances in pet food. J Pet Anim Nutr 13: 21-23.

18. Japan Pet Food Association: Types of pet food.

19. Pharmaceutical Society of Japan (2010) Standard methods of analysis for hygienic chemistry. Kanehara Shuppan Ltd., pp: 347-349.

20. Hirama Y, Nishimura K, Nakano M (1994) Effect of hydrochloric acid on determination of nitrite in Shiotarako (salted walleye pollack roe) by using diazotization method. Hokkaido Institute of Health Report 44: 69-72.

21. Inoue $T$ (2010) Influence of reagent concentration and reaction rate on colorimetry of nitrite ion by Saltman method. Bunseki Kagaku 59: 35-41.

22. Nomura C, Yoshimitsu M, Akutsu K, Obana H (2009) Studies on a small-scale method for the rapid determination of nitrite ion in foods. Osaka Prefectural Institute of Public Health Report 47: 17-20. 
Citation: Kobayashi J, Fujikake Y, Ishida M, Ikeda K, Sugiyama H (2016) Nitrite Concentrations in Commercial Dog Foods. J Vet Sci Technol 7: 369. doi: 10.4172/2157-7579.1000369

Page 5 of 5

23. Gamoh K, Sawamoto H (1992) Analytical methods for the determination of trace ion species in environmental water (Part 1) - Instrumental comparison for the determination of nitrite in spectrophotometric and ion chromatographic method. Research. Report of Kochi University 41: 17-27.

24. Horie M (2012) Basic knowledge of pretreatment for sample analysis Pretreatment method for analysis of food samples. Bunseki 12: 678-684.

25. Nagai K, Yoshida S (1976) On the interaction of $\mathrm{pH}$, temperature and air onstability of nitrite nitrogen in solution or gaseous state. The Agriculture, Forestry and Fisheries Research Information Technology Center 24: 85-91.

26. Noda H, Minemoto M, Eto S, Noda A, Matsuyama K (1984) Nitrite ion, its stability in an aqueous solution and disappearance from rabbit blood. Yakugaku Zasshi 104: 409-412.

27. Yoshii T, Asanuma N, Abe T, Iwamoto M, Hino T (2003) Nitrate and nitrite reduction by intestinal microbes of dogs and cats. J Pet Anim Nutr 6: 1-6.

28. Emi-Miwa M, Okitani A, Fujimaki M (1976) Comparison of the fate of nitrite added to whole meat, meat fractions and model systems. Agric Biol Chem 40: 1387-1392.
29. Nagano Prefecture: lida Meat Hygiene Laboratory.

30. Hioki S, Katou H, Itaya $\mathrm{H}$ (2000) Effect of salt and nitrite gives the characteristics of the meat processing food and sausage. Farm Technology Earnings Reports, Faculty of Agriculture, Hokkaido University 1: 96-97.

31. The Ministry of Health, Labour and Welfare (2011) Overview of the National health and nutrition examination survey 2011.

32. Japan Pharmaceutical Excipients Council (2005) Pharmaceutical additive safety data 2005.

33. Ministry of the Environment, Ministry of Agriculture, Forestry and Fisheries (2014) Status of enforcement of pet food safety low.

34. Visionbio Co (2016) Period and rate for inspection - Pet food safety inspection.

35. Oshima H, Ueno E, Saito I, Matsumoto H (2004) A comparative study of cadmium lead, mercury, arsenic, selenium, manganese, copper and zinc in brown rice and fish by inductively coupled plasma-mass spectrometry (ICP-MS) and atomic absorption spectrometry. Shokuhin Eiseigaku Zasshi 45: 270-276. 